\title{
Estimating aquatic phosphorus concentrations 30 metres down-current from a rainbow trout cage array
}

\author{
Gregor K. Reid ${ }^{* a}$ and Richard D. Moccia ${ }^{b}$ \\ Received 9th March 2007, Accepted 16th May 2007 \\ First published as an Advance Article on the web 11th June 2007 \\ DOI: $10.1039 / b 703585 c$
}

\begin{abstract}
Aquatic total phosphorus (Tot-P) is measured $30 \mathrm{~m}$ distant from rainbow trout (Oncorhynchus mykiss) cages, for regulatory compliance on the Canadian side of Lake Huron. The ability to predict changes in near-field Tot- $P$ concentrations from changes in production, or to explain nearfield concentrations in the event of compromised reference sites, would be very useful for managers and farmers. A logical first step in the development of a near-field model is the estimation of down-current Tot-P concentrations. A nutritional mass balance approach was used to calculate the amount of non-settleable Tot- $P$ which was divided by the corresponding flushing volume over four separate production periods. Despite a number of uncertainties, such as cage effects on flushing volume, the contribution of particulate phosphorus, fish distribution, feed conversion ratio, and ingestion-excretion time; accuracy (slope $=1.06)$ and precision $\left(r^{2}=0.75\right)$ of modelled estimates fit well with empirical results. It was concluded that $30 \mathrm{~m}$ down-current Tot- $P$ concentrations could be modelled under a diverse set of culture and environmental conditions, suggesting typical 'near-field' concentrations of Tot- $P$ can be explained on the basis of farm activities.
\end{abstract}

\section{Introduction}

Measurements of aquatic Tot- $P$ concentrations, $30 \mathrm{~m}$ distant from rainbow trout cage farms, are necessary for regulatory compliance in Lake Huron. ${ }^{1}$ The ability to model near-field concentrations of Tot- $P$, would assist in fish production decisions and improve our understanding of system dynamics.

Since phosphorus is typically a limiting nutrient in freshwater ecosystems, ${ }^{2}$ phosphorus loading from open water cageaquaculture has the potential to influence water quality. Indigestible phosphorus is egested in feces, while digestible phosphorus will be retained in the fish carcass, or excreted as orthophosphate. ${ }^{3}$ This is illustrated in Fig. 1. Knowledge of nutrient fractionation by cultured fish typically forms the basis of model inputs for predicting aquaculture's impacts.

Environmental impact modelling of cage-based aquaculture in freshwater is much less developed than in mariculture settings. Most published modelling efforts have focused on variants of traditional lake phosphorus models ${ }^{4-7}$ like Dillon-Rigler, ${ }^{8}$ Vollenweider ${ }^{9}$ and the OECD ${ }^{10}$ models; or mass balance, mechanistic approaches. ${ }^{11,12}$ While there has been some limited success using the Dillon-Rigler model to predict Tot- $P$ in small Scottish lochs where a fish farm was the major contributor of phosphorus, ${ }^{4}$ most iterations of the traditional lake phosphorus models usually over-predict water body concentrations by two fold. ${ }^{7}$ But there has been some success, mathematically correcting a variant of the OECD

${ }^{a}$ Department of Fisheries and Oceans Canada, St. Andrews Biological Station 531 Brandy Cove Road, St. Andrews, New Brunswick, E5B 2L9, Canada.E-mail: gregor@uoguelph.ca

${ }^{b}$ Aquaculture Centre, Department of Animal and Poultry Science,

University of Guelph, Guelph, Ontario, N1G 2W1, Canada. model improved predictions of Tot- $P$ for some Swedish lakes with fish cages. ${ }^{7}$

Regardless of the successes or failures, these models were designed to predict the mean phosphorus concentration of an entire water body in response to fish farm inputs. This approach is not necessarily practical in very large water bodies like the Great Lakes, where the potential for lake-wide eutrophication from aquaculture is negligible, and where it is the near-field concentrations of phosphorus that are of regulatory significance. Regulatory monitoring of fish cages in Ontario (Canada) reflects this approach, with sampling protocols designed to detect localized impacts. Ice-free, seasonal phosphorus sampling is required at distances $30 \mathrm{~m}$ from fish cage arrays, within the depths of the cages, at every side not attached to shore. ${ }^{1}$

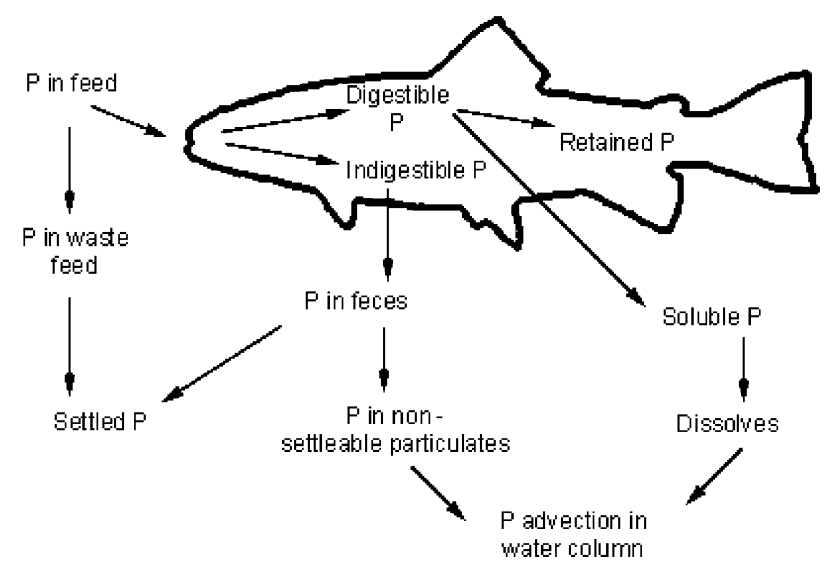

Fig. 1 Schematic of phosphorus (P) partitioning in salmonid culture. 
Reference sites for aquaculture monitoring are locations assumed to be representative of 'normal' or background water quality conditions either in similar, but unfarmed water bodies, ${ }^{7}$ or from within the same water body. ${ }^{1}$ There is some subjectivity in the choice of suitable reference sites for assessing water quality impacts from cage fish farms within large water bodies. If the reference site is too close to the cages, there is a risk the farm may influence the very waters intended to be a basis for comparison. ${ }^{1}$ If the reference site is too far removed, it may not be representative of localized conditions around the farm, and could be influenced by non-farm related nutrient inputs. Failure to credibly explain Tot- $P$ measurements in the event of compromised reference sites could make regulatory enforcement, legal liability, or farm management decisions extremely difficult.

Methods that can predict or explain near-field water quality changes at cage sites would be of use, especially where the reliability of reference sites is questionable. If near-field concentrations of Tot- $P$ at a cage site can be successfully modelled, it follows that measured concentrations may be explained on the basis of farm activities. The ability to successfully model these concentrations may also enable the estimation of flushing rates necessary to ensure that proposed changes in production level and phosphorus load does not exceed near-field Tot- $P$ compliance limits.

In order to estimate near-field Tot-P concentration in waters around fish cages, the mass of non-settleable Tot- $P$ produced, and the dilution factor caused by volume and flushing rates needs to be determined. There has been some success applying a similar approach to estimate nutrient concentrations in rivers that receive effluent discharges from land-based rainbow trout farms. ${ }^{13}$ However, while nutritional mass balance models are reasonably well developed, ${ }^{13,14}$ determining water volume flushed through fish cages can be difficult, due to the affects of cages on hydrodynamics. Drag is produced as water flows through the cage netting and around cage structures, ${ }^{15,16}$ thereby reducing the flow velocity and increasing turbulence in adjacent waters. Drag and turbulence are affected by: the ratio of net thread to space, referred to as solidity ${ }^{15}$ or porosity; ${ }^{17}$ flexibility of the cage; ${ }^{18}$ angle of attack; ${ }^{15,17}$ number of net panel crossings; ${ }^{15}$ lift; ${ }^{19}$ space between cages; ${ }^{15,16}$ the drag coefficient (or roughness) of the individual net threads; ${ }^{15,16}$ and current velocity. ${ }^{20}$ Wakes can be generated at multiple scales, ranging from individual net threads ${ }^{15,16}$ to vortical flow generated by the general obstruction of water flow caused by the cages; ${ }^{17}$ the amount of spread a function of the distance travelled. ${ }^{15,16}$ These parameters are seldom constant. Fouling of the mesh can alter the thread drag coefficients and change the porosity. The affect of several dozen tonnes of fish on flow fields appears to be largely unknown.

Modelling cage-affects on flushing volume would be extremely complex and the necessary data inputs would be arguably impractical to acquire at functional commercial fish farms. However, reviewing the precision and accuracy of near-field Tot- $P$ estimates made without attempting to correct for cage affects on flushing volume, may be one method to help determine how such influences affect model estimates and what, if any, correction factors should be investigated.

Therefore, this study aimed to estimate mean daily Tot- $P$ concentrations, $30 \mathrm{~m}$ down-current of a rainbow trout farm in Lake Huron, combining estimates of nutrient loading with 'uncorrected' flushing volumes, as a first step to modelling 'near-field' Tot- $P$ concentrations. A mass balance waste estimation model ${ }^{14}$ was modified and combined with a onedimensional flushing calculation to estimate down-current concentrations of Tot- $P$ during four separate production periods.

\section{Experimental}

The modelling and field validation was tested at an operating commercial fish farm where variations in animal husbandry and environmental conditions are dynamic. Four modelling periods (T1-T4) of differing environmental, husbandry and production outputs were chosen to ensure a number of diverse conditions for testing.

\section{Total phosphorus and current measurements}

Tot- $P$ water sampling details and current profiling specifics are detailed in Table 1. To avoid entangling the vertical point

Table 1 Total phosphorus sampling and current profiling details

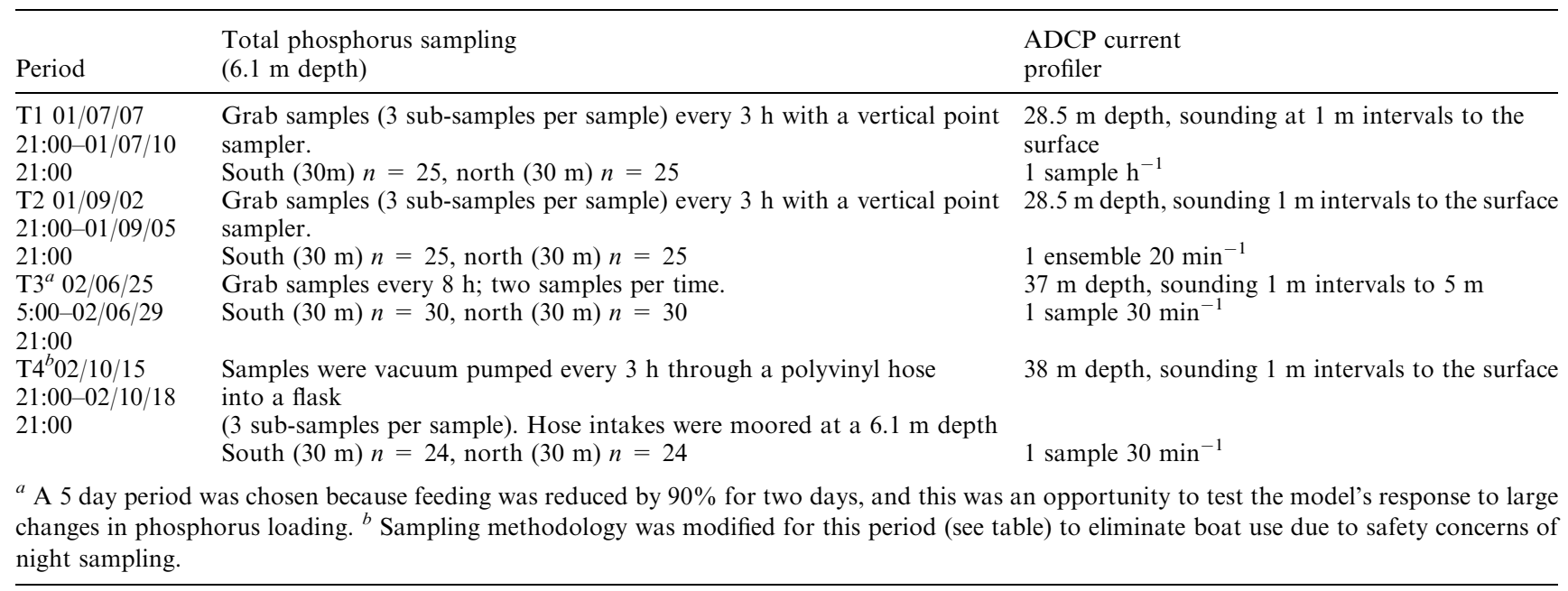



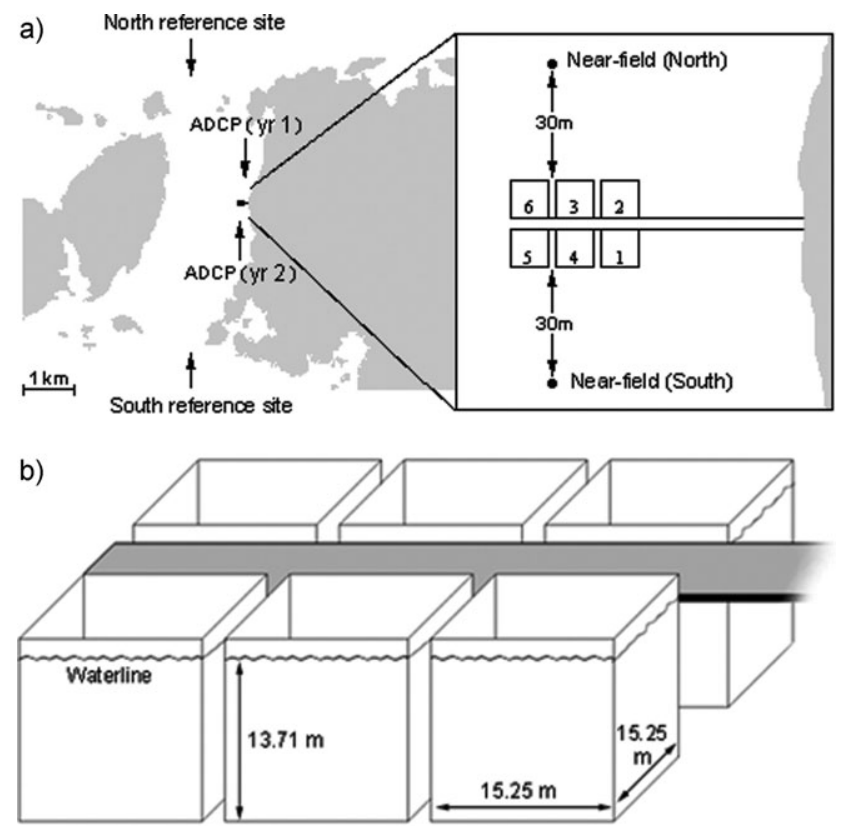

Fig. 2 (a) Site configuration, sampling locations and acoustical Doppler current profiler (ADCP) locations at the commercial farm site in the Wabauno Channel (North Channel, Lake Huron). (b) Schematic showing cage dimensions.

sampler with mooring cables, the $30 \mathrm{~m}$ sampling locations were moved slightly west of the centre of the farm (Fig. 2a). Reference sites were sampled a minimum of two times during each modelling period. Tot- $P$ was analyzed using a colorometric procedure for low concentration Tot- $P .{ }^{21}$ Samples were digested for $30 \mathrm{~min}$ in sulfuric acid-persulfate media at $121{ }^{\circ} \mathrm{C}$. The lower level of detection for the analytical procedure was $1 \pm 0.3 \mu \mathrm{g} \mathrm{L}^{-1}$ or less (analytical level of quantification was $5 \pm 1 \mu \mathrm{g} \mathrm{L}^{-1}$ or less). Lower levels of detection and quantification were determined in accordance with procedures from Standard Methods for the Examination of Water and Waste Water. ${ }^{22}$ For quality assurance, calibration standards and certified reference material for Tot- $P$ (from the National Water Research Institute of Canada) were analyzed throughout the entire procedure (assays on CRMs were within $\pm 0.5 \mu \mathrm{g} \mathrm{L}{ }^{-1}$ of certified values).

Current velocities and directions were measured with an acoustical Doppler current profiler (ADCP, RDI work horse model, $600 \mathrm{kHz}$ ) positioned on the lake bottom. Deployment and data collection details are show in Fig. 2 and Table 1. Given the position of $30 \mathrm{~m}$ sampling locations, and assuming that the current direction travels more or less linearly through the cage array, the sampling locations would be within downcurrent waters when flow direction traveled within $22^{\circ}$ east of either a north or south vector, and $45^{\circ}$ west of a north or south vector. Consequently, samples taken when water flow was travelling within these parameters were classified as either upcurrent or down-current flow through the site, respectively. Since ADCPs were deployed some distance beyond the $30 \mathrm{~m}$ monitoring locations, up and down-current classifications are considered approximations, since direct measures of current flow between the cage array and the $30 \mathrm{~m}$ monitoring point were not possible. Times in which the current flow was less than $1 \mathrm{~cm} \mathrm{~s}^{-1}$ were omitted, since these flows approached the measurement error of the ADCP. Samples taken where the current direction changed during sample collection were also omitted.

\section{Estimation of total phosphorus loading}

The farm operator recorded daily feed inputs for each fish cage. Waste estimates were made using a modified waste estimation model. ${ }^{14}$ Estimation of non-settleable Tot- $P$ is detailed in Eqns (1). The mass of soluble phosphorus excreted is simply the estimate of phosphorus digested by the fish minus the amount of phosphorus retained in the carcass (eqn (1i)). It is assumed that the soluble phosphorous $(\mathrm{Sol}-\mathrm{P})$ loading from an entire cage is the $\mathrm{g}$ fish ${ }^{-1}$ value multiplied by the number of fish in the cage. Fecal phosphorus equals phosphorus ingested minus the phosphorus digested (eqn (1ii)). Tot- $P$ in these estimates does not include contribution from waste feed because it is assumed that feed pellets will not travel $30 \mathrm{~m}$ distance (within the cage depth) under typical current regimens, but instead includes all soluble excreted phosphorus and non-settelable fecal phosphorus (eqn (1iii)). The amount of non-settleable phosphorus (as fine, fecal particulates) is calculated (eqn (liv)) as a percentage of the total phosphorus loaded. ${ }^{23}$ Retained phosphorus is the difference between the total carcass phosphorous of the initial and final body weights (eqn (1v)) over the period of interest. The carcass phosphorus content (as a percent) is determined by a regression equation ${ }^{22}$ where phosphorus in the carcass is a function of body weight (eqn (1vi)). This regression for phosphorus carcass composition was developed with trout from the same commercial farm used in this study and one other Ontario cage-farm. ${ }^{24}$ The estimated final body weight is calculated by dividing the FCR (wt feed/wt fish gain) by total weight of the feed consumed (eqn (1vii)).

Eqns (1): Estimation of non-settleable total phosphorus loading

Mass of soluble phosphorus Sol-P $=((F A-A F W)$

$$
\left.\times P_{\text {feed }} \times P_{\mathrm{di}}\right)-R P(\mathrm{~g})
$$

where $(F A-A F W)=$ amount of feed ingested and $((F A-$ $\left.A F W) \times P_{\text {feed }} \times P_{\mathrm{di}}\right)=$ amount of phosphorus digested

$$
\begin{gathered}
P_{\text {fecal }}=(F A-A F W) \times P_{\text {feed }} \times\left(1-P_{\mathrm{di}}\right)\left(\mathrm{g} \mathrm{fish}^{-1}\right) \\
T o t-P=P_{\text {fecal }}+S o l-P\left(\mathrm{~g} \mathrm{fish}^{-1}\right) \\
P_{\mathrm{ns}, \text { fecal }}=\text { Tot- } P \times N \text { Set }-P\left(\mathrm{~g} \mathrm{fish}^{-1}\right) \\
R P=F B W \times P_{\text {carass }}-I B W \times P_{\text {carcass }}\left(\mathrm{g} \mathrm{fish}^{-1}\right) \\
P_{\text {carcass }}=0.0035\left(\mathrm{~g} \mathrm{fish}^{-1}\right)+0.1076\left(\mathrm{~g} \mathrm{fish}^{-1}\right) \\
F B W=(1 / F C R)(\text { Feed }-A F W)\left(\mathrm{g} \mathrm{fish}^{-1}\right) \\
\text { Tot- } P_{\mathrm{ns}}=P_{\mathrm{ns}, \text { fecal }}+\text { Sol-P }\left(\mathrm{g} \mathrm{fish}^{-1}\right)
\end{gathered}
$$

Feed conversion ratios (FCRs) were calculated from farm weight and growth data collected by the farm operator over two production seasons. Model constants are shown in Table 2.

Estimation of aquatic Tot- $P$ concentration is detailed in Eqns (2). The non-settleable total phosphorus output (as 
Table 2 Model constants ${ }^{a}$

\begin{tabular}{ll}
\hline Constant & Source \\
\hline$A F W=0.05$ & Cho and Bureau ${ }^{14}$ \\
$P_{\text {feed }}=0.0112$ & Analysis (Laboratory Services, University of Guelph, Guelph, ON, Canada) \\
$P_{\mathrm{di}}=0.45$ & K. Were, Skretting (then, Moore Clark), personal communication, 2003 \\
$N S e t-P=0.10$ & Derived from Coloso et $_{\text {al. }}{ }^{23}$ \\
$(t-1)=12 \mathrm{~h}$ & Reid $^{25}$ \\
${ }^{a}$ Estimation of total phosphorus concentration in the site down-current at $30 \mathrm{~m}$. \\
\hline
\end{tabular}

mass) is divided by the estimated daily flushing volume (uncorrected) and added to the measured Tot- $P$ concentration upcurrent; to estimate the down-current concentration (eqn (2i)). This approach is sometimes referred to as uptake-clearance. ${ }^{26}$ An uncorrected, one dimensional flushing equation was approximated using $6 \mathrm{~m}$ depth current velocity data. This depth is just above the mid-depth of the cages, and is the same depth as Tot- $P$ sample collection. The inter-cage volume between east-west adjacent cages was included in the flushing calculation.

For ease of description, the orientation of adjacent cages along the direction of current flow will be referred to as a column. The farm Tot- $P$ contribution is subsequently a mean of the exiting down-current concentrations from all columns (eqn (2iii)). The resulting down-current phosphorus concentrations are assumed to be additive across adjacent cages (eqn (2iv)). The non-settleable Tot- $P$ contribution from an individual cage is a function of the soluble phosphorus and nonsettleable fecal particulates (eqn (2v)). The non-settleable fecal fraction is included since it is assumed that it will travel with $S o l-P$ to $30 \mathrm{~m}$. The $(t-1)$ value accounts for the ingestion-excretion time delay. With the value used in this model (Table 2), Sol- $P$ generated from the afternoon feeding (one morning and afternoon feed daily) is included in the following day's loading value.

Eqns (2): Estimation of total phosphorus concentration in the site down-current at $30 \mathrm{~m}$.

$$
\begin{gathered}
{[\text { Tot-P }]_{\text {Down-current }, t}=[\text { Tot }-P]_{\mathrm{ns}, \text { farm }}+[\text { Tot }-P]_{\mathrm{In}}\left(\mu \mathrm{g} \mathrm{L}^{-1}\right)(2 \mathrm{i})} \\
F_{\text {cage }}=\text { number of flushings } \\
t
\end{gathered}
$$

where number of flushings $s_{t}=t /$ (cage length/current magnitude)

$$
\begin{gathered}
{[\text { Tot }-P]_{\mathrm{ns}, \text { farm }}=\text { Mean }[\text { Tot }-P]_{\mathrm{ns}, \text { Column }}\left(\mu \mathrm{g} \mathrm{L}^{-1}\right)} \\
{[\text { Tot }-P]_{\mathrm{ns}, \text { column }}=\sum[\text { Tot }-P]_{\mathrm{ns}, \mathrm{cage}}\left(\mu \mathrm{g} \mathrm{L}^{-1}\right)} \\
{[\text { Tot }-P]_{\mathrm{ns}, \mathrm{cage}}=\text { Tot }-P_{\mathrm{ns}(t-1)} F_{\text {cage }}{ }^{-1}\left(\mu \mathrm{g} \mathrm{L}^{-1}\right)}
\end{gathered}
$$

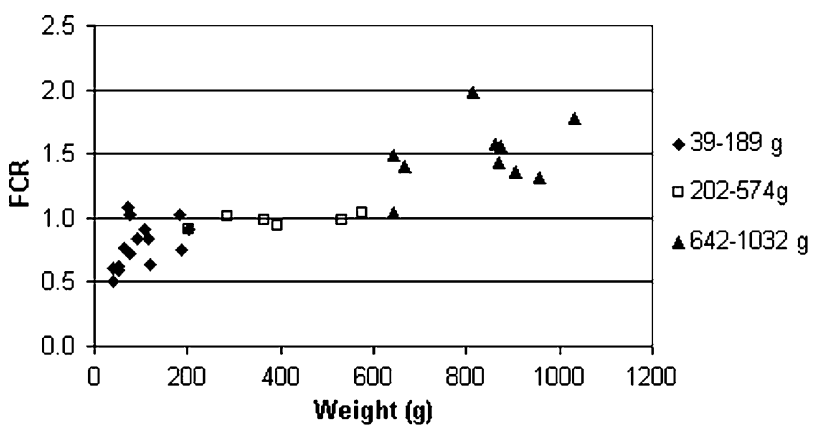

Fig. 3 Mean feed conversion ratios (FCR) for fish sizes 39-189 g, 202-574 $\mathrm{g}$ and $642-1032 \mathrm{~g}$ are $0.79,1.05$ and 1.49 , respectively.

\section{Results}

Environmental conditions, production details, and reference site Tot- $P$ concentrations are listed in Table 3. Farm FCRs are detailed in Fig. 3. Production and husbandry details and Tot- $P$ loading estimates are detailed in Table 4. Empirical measurements of current magnitude, Tot- $P$ in the site both up-current and down-current, and the number of samples that fall into this category are listed in Table 5. Results of individual modelling periods comparing estimated and measured means are detailed in Fig. 4. Estimated phosphorus concentrations had a reasonably good fit with measured values (Fig. 5; $R^{2}=0.75$ and a slope of 1.06 ).

\section{Discussion}

Despite a reasonably good fit between the model predicted concentrations and the measured values, there are several limitations that should be discussed. These are as follows:

(i) The estimation of particulate phosphorus reaching $30 \mathrm{~m}$.

(ii) Current flow and flushing estimates.

(iii) FCR assumptions.

(iv) Estimates of the delay time between ingestion and excretion.

Table 3 Environmental conditions

\begin{tabular}{lllll}
\hline Period & Thermocline $/ \mathrm{m}$ & Temperature ${ }^{a} /{ }^{\circ} \mathrm{C}$ & Secchi depth $/ \mathrm{m}$ & ${\text { Reference site } \text { Tot }-P^{b} / \mu \mathrm{g} \mathrm{L}{ }^{-1}}$ \\
\hline T1 & $\approx 22$ & 18 & $\approx 6.0 \mathrm{~m}$ & $5.5 \pm 0.4($ median $=5.5)$ \\
T2 & $\approx 14$ & 18 & $\approx 6.0 \mathrm{~m}$ & $5.1 \pm 0.3($ median $=4.6)$ \\
T3 & $\approx 12$ & 16 & $\approx 6.5 \mathrm{~m}$ & $4.0 \pm 0.1(\mathrm{median}=3.8)$ \\
T4 & Isothermal & 14 & $\approx 7.0 \mathrm{~m}$ & $4.6 \pm 0.3($ median $=4.7)$
\end{tabular}

${ }^{a}$ All water temperatures are averaged over the number of days in the sampling periods and through out the cage depth. ${ }^{b}$ Reference site samples (three sub-samples per sample) were taken at $6.1 \mathrm{~m}$, a minimum of two separate days during the sampling period. There was no significant difference between north and south reference sites $(P<0.05)$, so all samples were pooled. 
Table 4 Husbandry specifics and phosphorus loading estimates for individual cages

\begin{tabular}{|c|c|c|c|c|c|}
\hline Period & Cage number ${ }^{a}$ & Estimated biomass $^{b}(\mathrm{mt})$ & Mean fish size/g & Mean feed use ${ }^{d} / \mathrm{kg}$ day $^{-1}$ & Non-settleable total phosphorus ${ }^{e} / \mathrm{g} \mathrm{day}^{-1}$ \\
\hline \multirow{6}{*}{$\mathrm{T} 1$} & 1 & 31 & 1040 & 350 & 1059.7 \\
\hline & 2 & 28 & 890 & 350 & 1209.4 \\
\hline & 3 & 34 & 980 & 350 & 1059.7 \\
\hline & 4 & 31 & 995 & 450 & 1387.8 \\
\hline & 5 & 12 & 190 & 175 & 195.2 \\
\hline & 6 & 12 & 90 & 175 & 108.9 \\
\hline \multirow[t]{2}{*}{$\mathrm{T} 2$} & 5 & 28 & 450 & 400 & 773.4 \\
\hline & 6 & 33 & 280 & 400 & 722.9 \\
\hline \multirow{6}{*}{$\mathrm{T} 3$} & 1 & 29 & 910 & $0-500$ & $0-1129.0$ \\
\hline & 2 & 15 & 1070 & $0-300$ & $0-620.9$ \\
\hline & 3 & 36 & 735 & $0-500$ & $0-677.4$ \\
\hline & 4 & 17 & 1150 & $0-300$ & $0-1110.2$ \\
\hline & 5 & 7 & 105 & 125 & 79.3 \\
\hline & 6 & $4-14^{c}$ & 70 & 120 & 72.2 \\
\hline \multirow[t]{4}{*}{$\mathrm{T} 4$} & 2 & 15 & 290 & 275 & $0-354.0$ \\
\hline & 4 & 22 & 335 & 450 & 590.5 \\
\hline & 5 & 28 & 478 & 500 & 696.8 \\
\hline & 6 & 8 & 290 & 75 & 94.5 \\
\hline
\end{tabular}

${ }^{a}$ Only stocked cages are listed. ${ }^{b}$ Estimated by operator using mean feed conversion and fish sample weight. ${ }^{c}$ The range indicates a biomass change over the period (i.e. fish removed or added). ${ }^{d}$ Where a range occurs, the zero indicates at least one day without feeding. The upper value is a mean derived from fed days only. ${ }^{e}$ Where a range occurs, the zero indicates at least one day without theoretical excretion. The upper value is a mean estimate using fed days only.

(v) Vertical fish distribution.

(vi) Up-current vs. background Tot-P.

\section{Dispersion and measurement of particulate phosphorus}

Coloso et al. ${ }^{23}$ reported that $5-10 \%$ of Tot- $P$ is present as nonsettleable solids (particulates $<200 \mu \mathrm{m}$ ) in rainbow trout culture, depending on diet type. The upper limit of $10 \%$ was used as a crude estimator in the absence of settleable particulate advection data to account for an unknown, but assumed intermittent amount of settleable particulates advecting to near-field monitoring locations. While it was not possible to accurately determine the amount of settleable particulate phosphorus advecting to $30 \mathrm{~m}$; it is reasonable to assume this amount would be limited under typical current regimens. At a median settling rate of $1.15 \mathrm{~cm} \mathrm{~s}^{-1},{ }^{27}$ a current speed of $5.6 \mathrm{~cm}$ $\mathrm{s}^{-1}$ would be needed to transport feces released from the surface at the closest cage edge to a $6.1 \mathrm{~m}$ depth, $30 \mathrm{~m}$ distant. Feces released farther (65 $\mathrm{m}$ maximum) in the cage-array, would require greater speeds to reach this location. Feces released below $6.1 \mathrm{~m}$ anywhere within the array would presumably not reach this location. Current speeds at the site did exceed $5.6 \mathrm{~cm} \mathrm{~s}^{-1}$ for 3 of the 13 sampling days, suggesting that phosphorus in some settleable particulates could occasionally contribute to Tot- $P$ measurements along with, Sol-P and non-settleable phosphorus particulates.

\section{Current flow data and flushing estimates}

Since ADCPs were not deployed directly beneath the cages at the site, current vectors and velocities between the cages and $30 \mathrm{~m}$ down-current are approximations derived from more distant measurements. There will be some inaccuracies in these estimates given cage structural influences described previously.

Table 5 Daily mean current magnitudes and measured total phosphorus concentrations up/down-current at $30 \mathrm{~m}$

\begin{tabular}{|c|c|c|c|c|c|c|}
\hline \multirow[b]{2}{*}{ Period } & \multirow[b]{2}{*}{ Day } & \multicolumn{2}{|c|}{ Daily mean current velocity $/ \mathrm{cm} \mathrm{s}^{-1}$} & \multicolumn{3}{|c|}{ Daily mean $T o t-P / \mu \mathrm{g} \mathrm{L}^{-1}$} \\
\hline & & $n$ & & $n$ & Up-current $(30 \mathrm{~m})$ & Down-current $(30 \mathrm{~m})$ \\
\hline \multirow[t]{3}{*}{$\mathrm{T} 1$} & 1 & 2 & $2.75 \pm 0.95$ & 2 & $6.47 \pm 0.44$ & $9.67 \pm 3.34$ \\
\hline & 2 & 4 & $2.63 \pm 1.14$ & 4 & $7.35 \pm 0.49$ & $10.26 \pm 2.18$ \\
\hline & 3 & 3 & $2.20 \pm 0.26$ & 3 & $6.60 \pm 1.20$ & $10.26 \pm 0.91$ \\
\hline \multirow[t]{3}{*}{$\mathrm{T} 2$} & 1 & 1 & $3.90^{a}$ & $1^{b}$ & $4.82 \pm 0.09$ & $5.44 \pm 0.43$ \\
\hline & 2 & 8 & $4.74 \pm 1.52$ & 8 & $4.05 \pm 0.24$ & $4.53 \pm 0.26$ \\
\hline & 3 & 2 & $2.40 \pm 1.30$ & 2 & $5.18 \pm 0.42$ & $5.64 \pm 0.62$ \\
\hline \multirow[t]{5}{*}{$\mathrm{T} 3$} & $1^{c}$ & 0 & $\mathrm{~N} / \mathrm{A}$ & 0 & $\mathrm{~N} / \mathrm{A}$ & $\mathrm{N} / \mathrm{A}$ \\
\hline & 2 & 9 & $7.27 \pm 1.35$ & 6 & $4.24 \pm 0.52$ & $6.30 \pm 1.09$ \\
\hline & 3 & 9 & $8.54 \pm 0.40$ & 6 & $3.57 \pm 0.20$ & $5.23 \pm 0.15$ \\
\hline & 4 & 3 & $8.97 \pm 0.73$ & 2 & $4.06 \pm 0.28$ & $5.80 \pm 0.34$ \\
\hline & 5 & 3 & $3.70 \pm 0.56$ & 2 & $5.05 \pm 0.54$ & $7.41 \pm 1.26$ \\
\hline \multirow[t]{3}{*}{$\mathrm{T} 4$} & 1 & 5 & $3.60 \pm 0.42$ & 5 & $4.26 \pm 0.23$ & $5.80 \pm 0.27$ \\
\hline & 2 & 6 & $4.78 \pm 1.09$ & 6 & $4.82 \pm 0.14$ & $6.76 \pm 0.38$ \\
\hline & 3 & 9 & $4.76 \pm 0.78$ & 9 & $4.32 \pm 0.20$ & $8.57 \pm 0.34$ \\
\hline
\end{tabular}

${ }^{a}$ All \pm values are standard error. Single sample, no standard error. ${ }^{b}$ Standard error for the up and down-current samples were calculated from three, sub-samples. ${ }^{c}$ No samples could be categorized up/down-current for this day. 


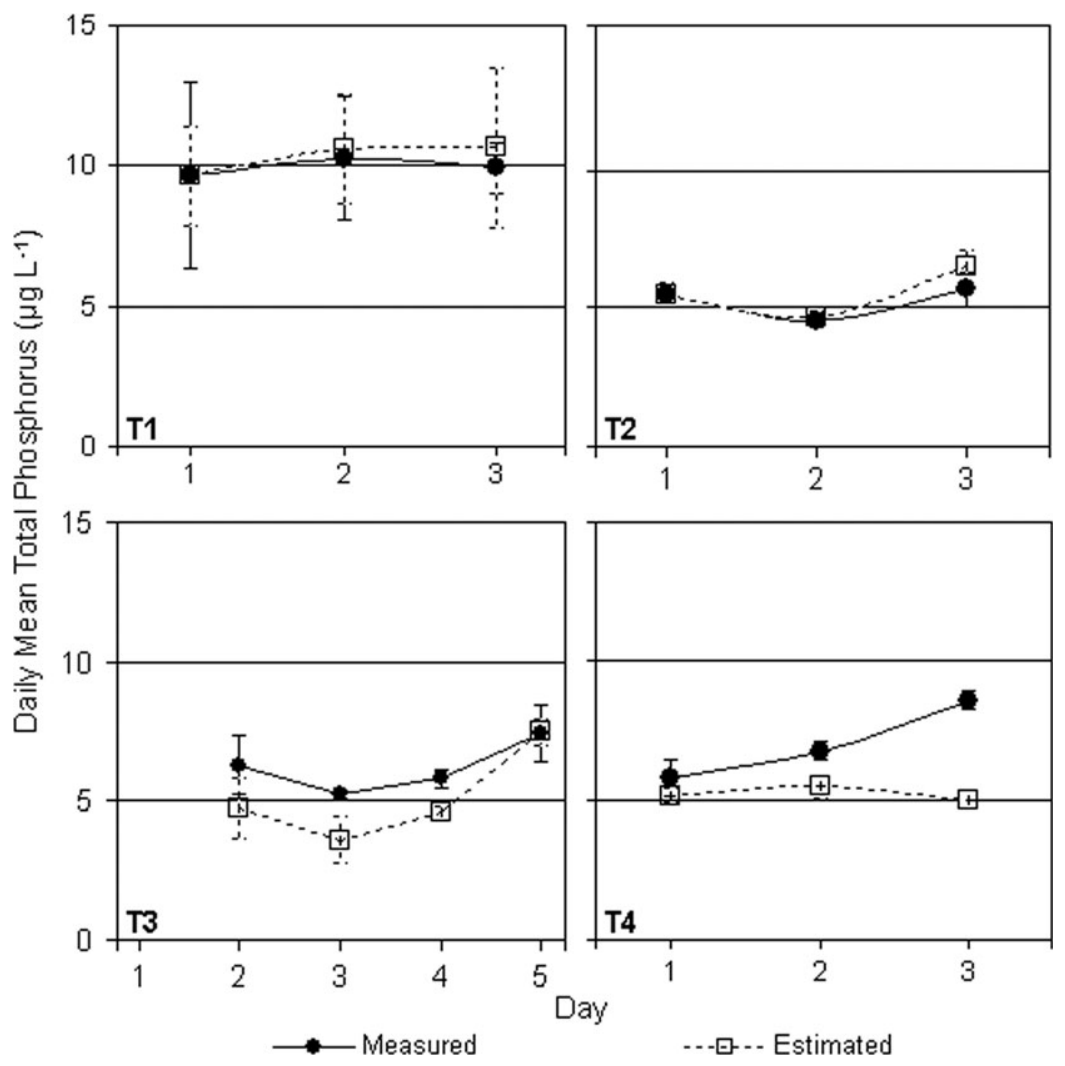

Fig. 4 Measured $v s$. estimated Tot- $P$ concentrations $30 \mathrm{~m}$ down-current for individual sampling periods (T1-T4). Error bars are \pm one standard error.

However, in all cases, daily average down-current Tot-P concentrations were higher or the same as up-current concentrations. Results from a simultaneous study by the authors using the same current data found variations and correlations between daily mean Tot- $P$, dissolved oxygen ( $\%$ saturation) and $\mathrm{pH}$ increased from the up-current to down-current locations. ${ }^{28}$ This is what would be expected if mean current flow was generally linear with a reasonable approximation of up/ down current locations.

Another source of uncertainty in the modelled estimates is the increased sensitivity of Tot- $P$ estimates at low current speeds. For example, a reduction in the current velocity by half, will double the concentration independent of a constant

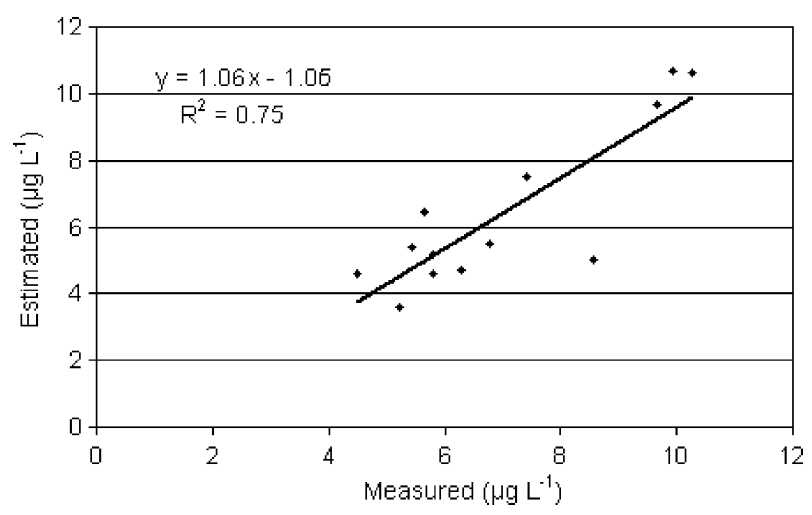

Fig. 5 Model fit for total phosphorus concentrations. loading rate. However, a reduction in current magnitude of $1 \mathrm{~cm} \mathrm{~s}^{-1}$ at a nominal current speed of $10 \mathrm{~cm} \mathrm{~s}^{-1}$ represents a $10 \%$ change, whereas a reduction of current magnitude by $1 \mathrm{~cm} \mathrm{~s}^{-1}$ at nominal velocities of $2 \mathrm{~cm} \mathrm{~s}^{-1}$ is a reduction of $50 \%$. Uncertainty in current measurements therefore becomes much larger at slow current speeds, and high concentration estimates resulting from low flushing will potentially produce more error than low concentration estimates resulting from high flushing.

\section{Vertical fish distribution}

One model assumption is that the fish are uniformly distributed through the cage. However, if fish are distributed at different densities within the depth of the cage itself, varying concentrations of phosphorus could occur at these depths under the same current regimen, depending on urination and defecation locations. It is well known that fish will move to the surface during a 'feeding frenzy' and can distribute themselves according to temperature preference and social hierarchies. There is some evidence of a non-uniform vertical fish distribution at the site. In a simultaneous study by the authors, the mean ice-free season Tot- $P$ profile at the site centre showed surface and $6.1 \mathrm{~m}$ Tot- $P$ concentrations were significantly higher than the $12.2 \mathrm{~m}$ concentrations located just above the $13.7 \mathrm{~m}$ cage bottom depth. ${ }^{28}$ The mean seasonal current velocity at these depths suggests that the concentration differences between various depths are not likely a reflection of current magnitude. This might indicate that fish distribution 
was not as dense at the bottom of the cages. If this is the case, then the actual flushing volume containing the fish at the cage mid-depth was less than expected, resulting in higher actual concentrations at the $6.1 \mathrm{~m}$ depth.

\section{Feed conversion ratio}

Expected FCR's and weight of feed fed was used to estimate growth in the absence of actual fish sample weights. Mathematically, the FCR will not affect estimates of solid fecal waste, but it is essential for soluble waste estimates in the absence of actual initial and final carcass compositions. Ideally the soluble phosphorus estimation component incorporates actual carcass composition and weight gain for the mass balance estimates. ${ }^{14}$ However, the estimate resolution here is in the scale of days. Daily measurements of weight gain and carcass composition are impractical and samples would certainly fall within the error range of empirical measurements, given the relatively small daily changes in growth and nutrient deposition. However, theoretical estimates of weight gain using FCR (eqn (1vii)) to estimate nutrient retention (eqn (1v), eqn (1vi)) can accommodate this level of resolution. The FCR data measured at the farm did not easily fit a conventional regression, but the data grouping did suggest that a 'moving average' approach was one option to match FCRs to fish size. Consequently three different size ranges were assigned a mean FCR, accordingly (Fig. 3). Nevertheless, the use of theoretical FCR and approximation of FCR for a range of fish sizes has the potential to introduce some error.

\section{Time between ingestion and excretion}

Fish do not instantaneously excrete waste from ingested feed. If phosphorus loading is to be predicted over short time frames such as a single day, the time between ingestion and excretion may need to be accounted for. This may not be crucial if the day-to-day feeding regimen is frequent in terms of number of feeding events per day and consistency with respect to times of feeding. It would not likely be necessary to distinguish soluble phosphorus generated from one feeding to the next as presumably the same amount of excretion will occur from each feeding episode. However, this time-lag may need to be addressed during substantial changes in daily feeding regimen, such as in T3 of this study. Rainbow trout soluble phosphorus excretion peaks approximately $12 \mathrm{~h}\left(15^{\circ} \mathrm{C}\right)$ after feed consumption. ${ }^{25}$ Therefore, at the present stage of model development, this time lag was used for all periods. It was difficult to validate this approach for periods with similar daily feed inputs (T1, T2 and T4) and different temperatures. However, the relatively similar slopes between daily means of measured and estimated Tot-P during T3 (Fig. 4), where daily feed consumption changed dramatically and mean water temperatures were $16{ }^{\circ} \mathrm{C}$, suggested this approach was adequate.

\section{Up-current $v s$. background total phosphorus}

One limitation in applying this modelling approach is the need to determine the up-current Tot- $P$ concentration entering the site. It cannot safely be assumed that the water body background concentration is always the same as the up-current concentrations. This was demonstrated during T1 where, compared to the other periods, it had the highest production levels and the slowest current velocities. Up-current Tot-P was higher than the background concentration, possibly due to previously loaded phosphorus travelling back to the farm due to current oscillations. The difference between background and up-current concentrations here was unlikely due to other anthropogenic influences, since there was no significant difference $(P<0.05)$ in reference site concentrations between modelling periods. The occurrence of an up-current concentration that is higher than the background concentration poses a potential source of error for the use of this approach in predictive scenarios and caution is warranted.

\section{Conclusions}

While it is possible that model error propagated in a manner resulting in a coincidental good fit, a more logical explanation involves the sampling distance. As previously described, flow velocity and flushing rates are reduced as water travels through net panels, and wake spread increases as a function of distance traveled. One process theoretically increases solute concentration and the other process causes a theoretical decrease in solute concentration. This suggests that at some distance down-current, the effects of the two processes on solute concentrations will 'equilibrate', and concentrations would be the same as if the cage array had no effects on hydrodynamics at all. No doubt this distance will vary depending on current magnitude and other factors. However, it may have been the case that the sampling distance occurred where these effects 'averaged' under the daily mean current conditions at the study site. It is plausible that at a certain distance from the farm it may not be necessary to account for hydrodynamic influences of cages on flushing volume in model estimates. However, should estimates become sensitive to such affects; under conditions of good precision, a simple correction factor could be applied to produce accuracy. These explanations are speculative at this time and additional investigation is a logical next step for further research.

Despite the aforementioned uncertainties, this study's results suggest it is possible to estimate near-field Tot- $P$ concentrations down-current from rainbow trout cages within daily time scales. Ultimately, our understanding of water quality response to cage-based rainbow trout production has improved.

\section{Nomenclature}

$\begin{array}{ll}A F W & \text { Apparent waste feed }(\%) \\ F A & \text { Feed allowance } / \mathrm{kg} \\ F B W & \text { Final body weight } / \mathrm{g} \mathrm{fish}^{-1} \\ F C R & \text { Feed conversion ratio/weight feed } \\ & \text { per fish weight gain } \\ I B W & \text { Initial body weight } / \mathrm{g} \text { fish } \\ \text { NSet }-P & \text { Non-settleable phosphorus coefficient } \\ & \text { (estimated percentage of particulate } \\ & \text { phosphorus less than } 200 \mu \mathrm{m}) \\ P_{\text {carcass }} & \text { Total phosphorus in carcass }(\%) \\ P_{\mathrm{di}} & \text { Dietary digestible phosphorus }(\%)\end{array}$




\begin{tabular}{|c|c|}
\hline$P_{\text {fecal }}$ & Total phosphorus in feces/g \\
\hline$P_{\mathrm{ns}, \mathrm{fecal}}$ & Non-settleable fecal phosphorus/g \\
\hline$P_{\text {feed }}$ & Total phosphorus in feed $(\%)$ \\
\hline$R P$ & $\begin{array}{l}\text { Assumed retained phosphorus } \\
\text { in carcass } / \mathrm{g}\end{array}$ \\
\hline Sol-P & Mass of soluble phosphorus/g \\
\hline Tot-P & Mass of total phosphorus/g \\
\hline Tot $-P_{\mathrm{ns}}$ & Non-setteable total phosphorus/g \\
\hline$F_{\text {cage }}$ & Total cage flushing volume $/ \mathrm{m}^{3}$ \\
\hline$(t-1)$ & $\begin{array}{l}\text { Estimated time between } \\
\text { ingestion and excretion } / \mathrm{h}\end{array}$ \\
\hline$[\text { Tot }-P]_{\mathrm{ns}, \text { Cage }}$ & $\begin{array}{l}\text { Concentration of non-settleable, } \\
\text { Tot-P from a cage } / \mu \mathrm{g} \mathrm{L}^{-1}\end{array}$ \\
\hline$[\text { Tot }-P]_{\mathrm{ns}, \text { Column }}$ & $\begin{array}{l}\text { Sum of cage Tot- } \mathrm{P}_{\mathrm{ns}} \text { contribution } \\
\text { along a current vector } / \mu \mathrm{g} \mathrm{L}^{-1}\end{array}$ \\
\hline$[\text { Tot }-P]_{\mathrm{ns}, \text { farm }}$ & $\begin{array}{l}\text { Non-settleable farm Tot-P } \\
\text { contribution as a concentration } / \mu \mathrm{g} \mathrm{L}^{-1}\end{array}$ \\
\hline$[\text { Tot }-P]_{\text {In }}$ & Mean up-current Tot-P/ $/ \mu \mathrm{g} \mathrm{L}^{-1}$ \\
\hline$[\text { Tot-P }]_{\text {Down-current }}$ & $\begin{array}{l}\text { Measured total phosphorus } \\
\text { concentration } 30 \mathrm{~m} \text { down- } \\
\text { current } / \mu \mathrm{g} \mathrm{L}^{-1}\end{array}$ \\
\hline Tot $-P_{\text {cage }}$ & $\begin{array}{l}\text { Mass of total phosphorus } \\
\text { produced from a single cage } / \mathrm{kg}\end{array}$ \\
\hline
\end{tabular}

\section{Acknowledgements}

Special thanks to Dan Glofcheskie and Jason Hughson of North Wind Fisheries Ltd. This research would not have been possible without their patience and support. Funding provided by the Northern Ontario Heritage Fund Corporation; Ontario Ministry of Agriculture, Food and Rural Affairs; Ontario Ministry of the Environment; Department of Fisheries and Oceans; and Environment Canada.

\section{References}

1 D. Boyd, M. Thorburn, T. Howel, Recommendations for the operational water quality monitoring at cage culture aquaculture operations, Environmental Monitoring and Reporting Branch, Ontario Ministry of the Environment, Rexdale, ON, Canada, 2001, p. 16.

2 J. J. Hudson, W. D. Taylor and D. W. Schindler, Nature, 1999, 400, 659-661.

3 D. P. Bureau and C. Y. Cho, Phosphorus utilization by rainbow trout (Oncorhynchus mykiss): estimation of dissolved phosphorus waste output, Aquaculture, 1999, 179, 127-140.

4 L. Kelly, Predicting the effect of cages on nutrient status of Scottish freshwater lochs using mass-balance models, Aquac. Res., 1995, 26, 469-477.

5 T. Johansson, L. Håkanson, K. Borum and J. Persson, Direct flows of phosphorus and suspended matter from a fish farm to wild fish in lake Southern Bullaren Sweeden, Aquacult. Eng., 1998, 17, 111-137.

6 L. Håkanson, L. Carlsson and T. Johansson, A new approach to calculate the phosphorous load to lakes from fish farm emissions, Aquacult. Eng., 1998, 17, 149-166.

7 T. Johansson and N. Nordvarg, Empirical mass balance models calibrated for freshwater fish farm emissions, Aquaculture, 2002, 212, 191-211.
8 P. J. Dillon and E. H. Rigler, A test of a simple nutrient budget model predicting the phosphorus concentration in lake water, J. Fish. Res. Board Can., 1974, 31, 1771-1778.

9 R. A. Vollenweider, The scientific fundamentals of the eutrophication of lakes and flowing waters, with particular reference to nitrogen and phosphorous as factors in eutrophciation, Technical report DAS/DSI/68.27, Organization of Economic Cooperation and Development, Paris France, 1968.

10 Organisation for Economic Co-operation and Development (OEDC), Eutrophication of waters. Monitoring, assessment and control, , OCED, Paris, 1982, p. 154.

11 L. Håkanson and L. Carlsson, Fish farming in lakes and acceptable total phosphorous loads calibrations simulations and predictions using the LEEDS model in lake Southern Bullaren, Sweden, Aquat. Ecosyst. Health Manage., 1998, 1, 1-24.

12 P. F. Hamblin and P. Gale, Water quality modelling of caged aquaculture impacts in lake Wosley North Channel of Lake Huron, J. Great Lakes Res., 2002, 28(1), 32-42.

13 E. Papatryphon, J. Petit, H. M. G. Van Der Werf, S. J. Kaushik and C. Kanyarushoki, Nutrient Balance Modeling as a Tool for Environmental Management in Aquaculture: The Case of Trout Farming in France, Environ. Manage., 2005, 35(2), 161-174.

14 C. Y. Cho and D. P. Bureau, Development of bioenergetic models and the FISH-PrFEQ software to estimate production feeding ration and waste output in aquaculture, Aquat. Living Resour., 1998, 11(4), 199-210.

15 G. Løland, Current forces on and water flow through and around floating fish farms, Aquacult. Int., 1993, 1, 72-89.

16 G. Løland, in Fish farming technology, ed. Reinertsen, Dahle, Jørgensen and Tvinnereim, Balkema, Rotterdam, 1993, pp. $177-183$.

17 C. E. Helsley and J. W. Kim, Mixing downstream of a submerged fish cage. A numerical study, IEEE J. Oceanic Eng., 2005, 30(1), $12-19$.

18 P. F. Lader and B. Enerhaug, Experimental investigation of forces and geometry of a net cage in uniform flow, IEEE J. Oceanic Eng., 2005, 30(1), 1-6.

19 F. Le Bris and D. Marichal, Numerical and experimental study of submerged supply nets Application to fish farms, J. Mar. Sci. Technol., 1998, 3, 161-170.

20 E. Fu, O. Sato, K. Nashimoto and K. Yamamoto, Fluid force on Simplified Models of Aquaculture Net Cage, Nippon Suisan Gakk., 1989, 55(7), 1211-1216.

21 Ontario Ministry of the Environment (OME), The Determination of Total Phosphorus in Water by Colourimetry, Laboratory Services Branch, Quality Management Office, Toronto, 1994.

22 APHA (American Public Health Association), AWWA (American Water Works Association), WEF (Water Environment Association), Phosphorus sample preparation, in Standard Methods for the Examination of Water and Wastewater, ed. L. S. Clesceri, A. E. Greenberg and A. D. Eaton, American Public Health Association, Washington, DC., 1998, 20th edn, pp. 4-142-4-143.

23 R. M. Coloso, K. King, J. W. Fletcher, M. A. Hendrix, M. Subramanyam, P. Weis and R. P. Ferraris, Phosphorus utilization in rainbow trout (Oncorhynchus mykiss) fed practical diets and its consequences on effluent phosphorus levels, Aquaculture, 2003, 220, 801-820.

24 D. P. Bureau, S. Gunther and C. Y. Cho, Chemical composition and preliminary theoretical estimates of waste outputs of rainbow trout reared in commercial cage culture operations in Ontario, $N$. Am. J. Aquacult., 2003, 65, 33-38.

25 G. K. Reid, Evaluation of nutrient loading dynamics from tank and cage cultured rainbow trout, $\mathrm{PhD}$ thesis, Department of Animal and Poultry Science, University of Guelph, ON, Canada, 2004, p. 205.

26 W. Silvert and J. Sowles, Modelling environmental impacts of marine finfish aquaculture, J. Appl. Ichthyol., 1996, 12, 75-81.

27 K. B. Wong and R. H. Piedrahita, Settling velocity characterization of aquaculture solids, Aquacult Eng., 2000, 21, 233-246.

28 G. K. Reid, I. McMillan and R. D. Moccia, Near-field loading dynamics of total phosphorus and short-term water quality variations at a rainbow trout cage farm in Lake Huron, J. Environ. Monit., 2006, 8, 947-954. 